\title{
Interactive responses of Quercus suber L. seedlings to light and mild water stress: effects on morphology and gas exchange traits
}

\author{
Jaime PUÉRtolas ${ }^{1,3}$, Marta PARdos ${ }^{2}$, María Dolores JiMÉnEZ ${ }^{1}$, Ismael ARANDA ${ }^{2}$, \\ José Alberto PARDOS ${ }^{1 *}$ \\ ${ }^{1}$ U.D. Anatomía, Fisiología y Genética, ETSI Montes, UPM, 28040 Madrid, Spain \\ ${ }^{2}$ CIFOR-INIA, Ap. Correos 8.111, 28080 Madrid, Spain \\ ${ }^{3}$ Current adress: Fundación CEAM, Universidad de Alicante, Dpto. Ecología, Campus de Sant Vicent del Raspeig, Apdo. 99 , 03080 Alicante, Spain
}

(Received 11 February 2008; accepted 19 April 2008)

\begin{abstract}
-
- The combined effect of water stress and light on seedlings of forest species is a key factor to determine the best silvicultural and afforestation practices in the Mediterranean area.

- The aims of this work was (1) to determine the optimal light level for the early development of cork oak seedlings under mild water stress and (2) to test if the combined effect of water stress and light followed the trade-off, the facilitation or the orthogonal hypothesis.

- Shade reduced instantaneous photosynthetic rates and water use efficiency in cork oak. However, seedlings grown under moderate shade (15\% of full sunlight) were capable to accumulate similar amount of biomass than those grown under more illuminated environments by increasing their specific leaf area. Absolute differences in net photosynthesis between light treatments were higher in well watered than in water stressed seedlings. However, the impact of both factors on overall growth was orthogonal.

- We concluded that cork oak development is impaired under deep shade (5\% of full sunlight) but it can be optimal under moderate shade (15\% of full sunlight) even under moderate water stress. Implications of these patterns on regeneration, cultivation and afforestation of cork oak are discussed.
\end{abstract}

cork oak / photosynthesis rate / water use efficiency / shade acclimation / foliar anatomy

\begin{abstract}
Résumé - Réponses interactives de semis de Quercus suber L. à la lumière et à un stress hydrique modéré : effets sur la morphologie et sur les caractéristiques des échanges gazeux.

- L'effet combiné du stress hydrique et de la lumière sur les semis est un facteur clé pour déterminer les meilleures pratiques pour la sylviculture et le reboisement dans la région méditerranéenne.

- Le but de ce travail a été (1) de déterminer le niveau optimal de lumière pour le développement précoce des semis de chêne liège soumis à un stress hydrique modéré et (2) de tester si l'effet combiné du stress hydrique et de la lumière suit l'hypothèse de compensation, de facilitation ou d'orthogonalité.

- L'ombre réduit le taux instantané de photosynthèse et l'efficience d'utilisation de l'eau chez le chêne liège. Cependant, les semis qui ont poussé sous une ombre modérée (15\% de la pleine lumière) ont été capables d'accumuler une biomasse totale similaire à celle des semis qui ont poussé sous de meilleures conditions d'éclairement en accroissant leur surface foliaire spécifique. Les différences absolues pour la photosynthèse nette, entre les traitements lumineux, ont été plus importantes pour les traitements bien alimentés en eau que pour les semis soumis à un stress hydrique. Cependant, l'impact des deux facteurs sur l'ensemble de la croissance a été orthogonal.

- Nous en avons déduit que le développement du chêne liège est diminué sous une ombre profonde (5\% du plein éclairement) mais il peut être optimal sous une ombre modérée (15\% du plein éclairement) même en conditions de stress hydrique modéré. Les implications de ces modèles pour le chêne liège ont été discutées pour ce qui concerne la régénération, la culture et le reboisement.
\end{abstract}

chêne liège / taux de photosynthèse / efficience d'utilisation de l'eau / acclimatation à l'ombre / anatomie foliaire

\section{INTRODUCTION}

The impact of the interaction between light and water availability in the physiology and performance of seedlings can greatly help to understand regeneration success and niche differentiation in Mediterranean ecosystems. This ecophysiological information is essential in process-based models of forest dynamics, which are poorly developed for Mediterranean ecosystems (Zavala and Zea, 2004). They are

*Corresponding author: puertsimon@yahoo.es necessary in the new scenario of increasing drought predicted by the models of climatic change for the Mediterranean region (Gibelin and Déqué, 2003) since it could alter the distribution and regeneration patterns of the forest species.

Cork-oak (Quercus suber L.) is one of the most important Mediterranean species from an economical and ecological point of view. It needs some shelterwood protection from overstory during the seedling stage for its establishment and early growth (Montero and Cañellas, 2003). Although, similarly to other Mediterranean species is capable to withstand 
dry periods, its drought resistance is intermediate amongst them. It is distributed along the centre and west of the Mediterranean basin, but the most important cork oak forests are located in the west of the Iberian Peninsula and North-Africa, where the influence of wet winds from the Atlantic Ocean provides abundant rainfall during the wet season. This preference for relatively humid climates within the Mediterranean area could make this species especially vulnerable to the predicted climate change.

The interaction between light and water stress may be a compromise between contradictory patterns of morphological and physiological response of seedlings (Kubiske et al., 1996; Pardos et al., 2005). Thus, it can be hypothesised that the combined effects of irradiance and water is characterised by a trade-off between drought tolerance and shade tolerance (Niinemets et al., 2004; Smith and Huston, 1989; Vance and Zaerr, 1991). This trade-off implies that plants adapted to shade would be worse adapted to drought than other seedlings growing under high light levels. However, there is strong evidence that under natural drought conditions, shade improves survival and physiological status through a decrease in evaporative demands and radiation loads, i.e. the facilitation hypothesis (Canham et al., 1996; Duan et al., 2005; Hastwell and Facelli, 2003; Holmgren, 2000; Rousset and Lepart, 1999). According to Holmgren et al. (1997) facilitation under shade conditions occurs when the improvement of water relation is more important than the cost imposed by dearth of light. Finally, an alternative hypothesis predicts that the combined effects of water stress and light availability are orthogonal (Castro-Díez et al., 2006; Nobel, 1999; Sack and Grubb, 2002). The validity of the three above-mentioned hypotheses will depend on the species, the intensity of water stress, the range of light studied, the traits considered and many other experimental features as seedling age or environmental conditions. The tolerance of the different species to the combined effect of drought and shade determines their distribution and regeneration niches (Prider and Facelli, 2004; Sack, 2004). The question addressed in this study is how does the early development of cork oak growing under moderate water deficit change across a light gradient.

There are different studies concerning the combined effect of light and water in morphological traits (Burslem et al., 1996; Sack and Grubb, 2002; Sack et al., 2003; van Hees, 1997), water relations (Aranda et al., 2001; Cavender-Bares and Bazzaz, 2000) and gas exchange parameters (Valladares and Pearcy, 2002; Welander and Ottoson, 2000). However, in most of these works, high light and water stress effects can be confounded, since light increases evaporation demands and, in turn, decreases soil humidity. In this study, in order to understand the interactions between water and light availability, drought was imposed to potted cork oak seedlings under a protocol that guaranteed the uniformity of soil water content across the different light treatments.

Length and intensity of drought are also determinant factors when studying water stress effect on plants. In this work, we wanted to study the effect of light and water availability on the early development of cork oak seedlings. Assuming that, under natural conditions, germination and part of the early growth occurs under optimum water availability and then seedlings are subjected to a slowly imposed moderate water stress, we tried to mimic these conditions. Further levels of water stress like those observed during mid and late summer in naturally grown seedlings of this species were outside the range of this study, but this high drought intensity do not affect early development but survival, since growth stops under higher water stress than that applied in this work (De Lillis and Fontanella, 1992).

The objectives of the study were (1) to determine the optimal light conditions for the development of Quercus suber seedlings under two different water availability levels and (2) to determine the combined effect of moderate drought and light on gas exchange and growth of Quercus suber seedlings, testing the three existing hypothesis (trade-off, facilitation, and orthogonal effects) for the early development of this species growing under moderate drought.

\section{MATERIAL AND METHODS}

\subsection{Plant material and treatments}

A factorial experiment of two factors (light and water) of four and two levels, respectively, with treatments replicated in three blocks, was designed to test for main effects and interactions on gas exchange, morphology and leaf anatomy on Quercus suber seedlings measured through one drying cycle. The four light levels varied from high to low photosynthetic photon flux density (PPFD); the two water levels were well watered versus moderate stress.

Acorns of cork oak (Quercus suber L.) from Valle del Tiétar provenance were collected in autumn 2000 and kept in moist plastic bags at $4{ }^{\circ} \mathrm{C}$. In April 2001, 500 acorns were placed in a seedbed at $25{ }^{\circ} \mathrm{C}$ for germination and two weeks after seeding, 120 germinated acorns were selected and transplanted to $3 \mathrm{~L}$ plastic pots $(20 \mathrm{~cm}$ depth) filled with a mixture of moss peat and fine sand (3:1, v:v). Five $\mathrm{g} \mathrm{L}^{-1}$ of a six months slow-release fertilizer (N:P:K 20:10:20 + micronutrients) was added to the substrate. Seedlings were grown in a greenhouse located at the INIA experimental centre (Madrid, Spain; $3^{\circ} 44^{\prime} \mathrm{W} ; 40^{\circ} 27^{\prime} \mathrm{N}$; 594 a.s.1.) under natural photoperiod $\left(30^{\circ} \mathrm{C}\right.$ day/ $10{ }^{\circ} \mathrm{C}$ night temperature, PPFD: $750-850 \mu \mathrm{mol} \cdot \mathrm{m}^{-2} \cdot \mathrm{s}^{-1}$ at midday) and kept well watered. On late-May 2001 seedlings were placed under a transparent plastic shelter to prevent the pots being watered by rain. The shelter had sides and ends opened to facilitate circulation of air.

Seedlings were randomly assigned to four light treatments. Ten plants were placed into each of twelve metal frames covered with different layers of neutral shade white cloth (Polysack Plastic Industries Ltd., Israel) to produce the four light environments. The percentage of PPFD under each light environment with respect to full sunlight during a sunny day was: HL1: $66-70 \%\left(34.7 \mathrm{~mol} \mathrm{~m}^{-2}\right.$ day $\left.^{-1}\right)$; HL2: 44-50\% (23.2 $\left.\mathrm{mol} \mathrm{m}^{-2} \mathrm{day}^{-1}\right)$; LL1: 14-16\% (7.9 mol m$\left.{ }^{-2} \mathrm{day}^{-1}\right)$; LL2: 5-6\% (2.6 $\left.\mathrm{mol} \mathrm{m}^{-2} \mathrm{day}^{-1}\right)$. Frames of the HL1 treatment had no shading coverage, but full sunlight could not be reached because of the effect of the plastic shelter.

Seedlings within each frame were randomly divided into two watering treatments, W (well-watered treatment) and S (water stressed treatment). Volumetric water content (VWC) in the substrate was monitored twice per week in the first $15 \mathrm{~cm}$ depth by means of time 
Table I. Results from the analysis of variance for morphological and leaf anatomy parameters. F-value and significance is provided (ns: $p>0.05 ; * 0.05 \geqslant p>0.01 ; * * 0.01 \geqslant p>0.001 ; * * * p \leqslant 0.001)$.

\begin{tabular}{llcc}
\hline Source of variation & Light $(\mathrm{L})$ & Watering $(\mathrm{W})$ & $\mathrm{L} \times \mathrm{W}$ \\
\hline Total leaf area & $3.50^{*}$ & $1.99(\mathrm{~ns})$ & $1.08(\mathrm{~ns})$ \\
Shoot biomass & $5.58^{* *}$ & $5.31^{*}$ & $0.46(\mathrm{~ns})$ \\
Root biomass & $6.81^{* * *}$ & $8.66^{* *}$ & $0.27(\mathrm{~ns})$ \\
Specific leaf area & $41.47^{* * *}$ & $1.21(\mathrm{~ns})$ & $0.30(\mathrm{~ns})$ \\
Leaf thickness & $78.47^{* * *}$ & $0.48(\mathrm{~ns})$ & $0.72(\mathrm{~ns})$ \\
Palisade parenchyma thickness & $84.49^{* * *}$ & $1.69(\mathrm{~ns})$ & $0.62(\mathrm{~ns})$ \\
Lacunal parenchyma thickness & $17.33^{* * *}$ & $0.23(\mathrm{~ns})$ & $0.80(\mathrm{~ns})$ \\
Epidermis thickness & $3.28^{*}$ & $1.91(\mathrm{~ns})$ & $0.32(\mathrm{~ns})$ \\
\hline
\end{tabular}

domain reflectometry (TDR; Trase System I, Soil Moisture Equipment Corp., USA). Water content in the W-treatment was maintained between $25 \%$ and $35 \%$ during the whole experiment. The S-treatment was allowed to dry down to $6.5 \%$ from 23 July to 15 August 2001, and maintained in this water content threshold from 16 August to 28 August 2001. Before reaching this VWC level, the volume of water supplied in the S-treatment for each irrigation was equal to the difference between the volume of water lost in the pot and the mean value of the volume lost in the LL2 treatment, which had the minimum water losses. With this procedure, homogeneity in VWC across light treatments was accomplished (light treatment was not statistically significant for VWC, $p>0.05$ )

\subsection{Measurements}

At the end of the experiment, on September 2, nine seedlings were harvested from each water $\times$ light combination ( 3 per block). Total leaf area was obtained with a Dias II image analyzer (Delta$\mathrm{T}$ Devices, Cambridge, UK). Dry weight of roots and shoots were measured after oven-drying at $65{ }^{\circ} \mathrm{C}$ for $48 \mathrm{~h}$. Two or three leaves from the upper third of each plant were selected for anatomical measurements. Samples were fixed in FAA (formalin-acetic-alcohol mixture) and kept in an alcohol-water mixture until they were processed. Leaves were immersed in a sodium hypochlorite and water mixture and three cross sections ( $5 \mu \mathrm{m}$ thick) were cut in each leaf with a microtome. The mean thickness of the leaf, the palisade and lacunal parenchyma layers and the epidermis layers were measured. Another 2-3 leaves next to those used for anatomical measurements were selected to accurately evaluate the specific leaf area (SLA; leaf area/leaf mass, in $\mathrm{cm}^{2} \mathrm{~g}^{-1}$ ).

Predawn water potential $\left(\Psi_{\mathrm{pd}}\right)$ measurements were made in five plants per each light $\times$ water regime on 14 August to assess the water stress achieved in each treatment. One leaf per plant was measured with a pressure chamber (PMS 1000, PMS Instrument Co., Corvallis, USA).

On 14 August and 28 August (at the beginning and the end of the maximum water stress period, respectively) five seedlings per each light $\times$ water regime combination were randomly selected for gas exchange measurements. Two seedlings were selected from two of the three blocks, while only one was selected from the randomly selected third. The small sample size used for physiological measurements made block effect negligible, so we decided not to consider it when planning the sample design. One leaf per plant from the upper half of the shoot was measured with a portable gas infrared analyzer (LCA4, ADC Ltd., Hoddesdon, UK). Net photosynthesis rate $(A)$

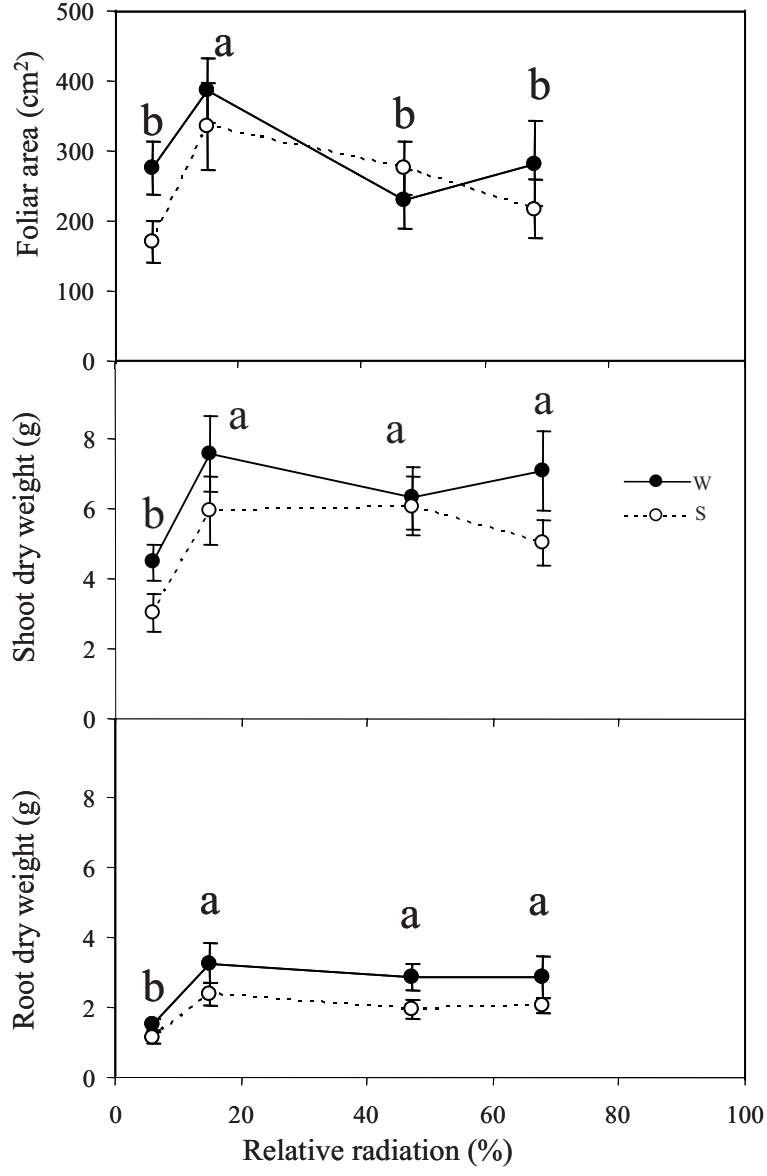

Figure 1. Relationship between morphological parameters (mean and standard error) and the relative radiation of the light treatments in $\%$ of full sunlight. (HL1: $66-70 \%$ of full sunlight; HL2: 44-50\%; LL1: $14-16 \%$; LL2: 5-6\%). Water treatments are also considered (W: well watered; S: water stressed) $(n=9$ for each light $\times$ water treatment). Since no interactions between light and water treatments were detected, different letters denote statistical differences between light treatments across the two water treatments (LSD, $p<0.05$ ).

stomatal conductance to water vapor $\left(g_{\mathrm{sw}}\right)$ and instantaneous intrinsic water use efficiency (IWUE), as the quotient between $A$ and $g_{\mathrm{sw}}$, were calculated and expressed on a leaf area basis. When leaves were smaller than the analyzer chamber $\left(6.25 \mathrm{~cm}^{2}\right)$, their projected area was measured with the image analyzer and the parameters were recalculated according to the actual area. Measurements were repeated three times during the day: at midmorning (8:30 to 9:30 solar time), at noon (12:00 to $13: 00)$ and in the afternoon (16:30 to $17: 30)$. During the measurements, seedlings were kept inside the frames, receiving the ambient irradiance of each light treatment. Photosynthetic photon flux density (PPFD), air temperature and relative humidity during the measurements were recorded with the gas analyzer and its radiation sensor. Vapor pressure deficit (VPD) was derived from the temperature and relative humidity measures. Measurements were made with two identical gas analyzer devices and the sequence of measurements was randomly chosen to avoid effects of variable light and VPD.

The day after, the same leaves were measured in the morning (10:00) under saturating light. Plants were raised outside the frames 


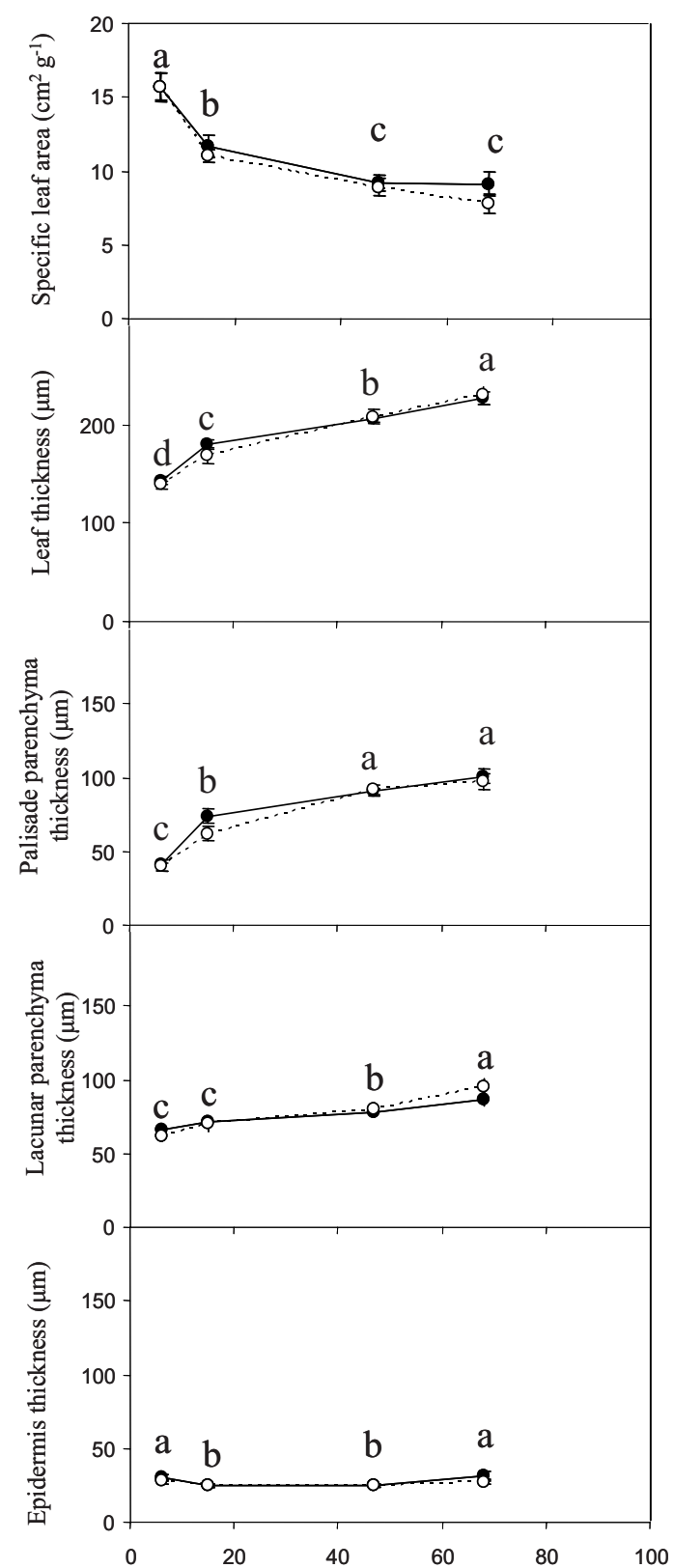

Figure 2. Relationship between foliar anatomy parameters (mean and standard error) and the relative radiation of the light treatments respect to the maximum (measured outside the plastic shelter) (HL1: 66-70\% of full sunlight; HL2: 44-50\%; LL1: 14-16\%; LL2: 5-6\%). Water treatments are also considered (W: well watered; $\mathrm{S}$ : water stressed) ( $n=9$ for each light $\times$ water treatment). Since no interactions between light and water treatments were detected, different letters denote statistical differences between light treatments across the two water treatments (LSD, $p<0.05$ ).

5-10 min before the measurements, time enough to reach maximum photosynthetic capacity and not too long to induce photoinhibition. Measurements were made using a lamp which provided a PPFD of $1000 \mu \mathrm{mol} \mathrm{m} \mathrm{s}^{-2}$.
Table II. Mean value \pm standard error of photosynthetic photon flux density (PPFD; $\mu \mathrm{mol} \mathrm{m} \mathrm{m}^{-2} \mathrm{~s}^{-1}$ ) for each light treatment in each time of the measurements day. PPFD Measurements were made simultaneously to gas exchange measurements $(n=10)$. HL1: $66-70 \%$ of full sunlight; HL2: 44-50\%; LL1: 14-16\%; LL2: 5-6\%.

\begin{tabular}{llccc}
\hline & & $8: 30-9: 30$ & $12: 00-13: 00$ & $16: 30-17: 30$ \\
\hline \multirow{5}{*}{14 August } & HL1 & $745 \pm 7$ & $1005 \pm 4$ & $244 \pm 6$ \\
& HL2 & $418 \pm 4$ & $458 \pm 7$ & $328 \pm 8$ \\
& LL1 & $150 \pm 8$ & $168 \pm 7$ & $85 \pm 2$ \\
& LL2 & $88 \pm 4$ & $101 \pm 8$ & $54 \pm 6$ \\
\hline \multirow{5}{*}{28 August } & HL1 & $753 \pm 1$ & $825 \pm 1$ & $161 \pm 4$ \\
& HL2 & $398 \pm 6$ & $442 \pm 6$ & $114 \pm 4$ \\
& LL1 & $143 \pm 2$ & $168 \pm 1$ & $87 \pm 3$ \\
& LL2 & $70 \pm 3$ & $110 \pm 6$ & $74 \pm 3$ \\
\hline
\end{tabular}

\subsection{Statistical analysis}

ANOVA with repeated measures was employed for gas exchange parameters measured under ambient light for the two measurement dates separately. Light treatment and water regime were considered fixed between-subjects effects in the model, while time of the day was the within-subjects effect. For each water regime in each time of the day and measurement date, light treatment means were grouped into homogenous groups according to LSD test. Two-way fixed effects ANOVA was used for gas exchange parameters measured under saturating light and water potential measurements, with light treatment and water regime as main effects. Light treatment means were also grouped into homogenous groups by LSD test. Since block did not affect the studied parameters in none of the analyses, it has been excluded from the presented results for clarity. ANOVA analyses were conducted using Statistica 6.0 (StatSoft, Inc., Tulsa, USA).

In the first measurement date, two linear regression analyses of photosynthesis rate with stomatal conductance were carried out for the measures made both under ambient light in the morning and under saturating light. After plotting the data, two different groups could be clearly distinguished: the high light group (HL = HL1 + HL2) and the low light group (LL = LL1 + LL2). Homogeneity of slopes and intercepts was tested to compare both groups (see Pardos et al., 2005 for details of methodology). Regression analyses and homogeneity tests were conducted using Statgraphics Plus 4.1 (Manugistics Inc., Rockville, USA).

\section{RESULTS}

\subsection{Morphology and foliar anatomy}

Light and water treatment affected seedling morphology (Tab. I). No interaction between both factors was found for none of the considered parameters. Biomass was lower in water stressed seedlings compared to well watered seedlings and in the most shaded treatment compared to the rest of the light treatments (Fig. 1). LL1 plants had the greatest foliar area, but no differences were found between water treatments for this parameter.

Light availability increased the thickness of the leaf (Tab. I). This increase was mainly due to the effect of light on palisade parenchyma, while the differences between light treatments in lacunal parenchyma and epidermis were moderate 
Table III. Results from the analysis of variance with repeated measurements for the gas exchange parameters measured under ambient light in the two measurement dates. F-value and significance is provided (ns: $p>0.05 ; * 0.05 \geqslant p>0.01 ; * * 0.01 \geqslant p>0.001 ; * * * p \leqslant 0.001$ ).

\begin{tabular}{|c|c|c|c|c|c|c|c|}
\hline \multicolumn{2}{|c|}{ Source of variation } & Light (L) & Watering (W) & Time of the day $(\mathrm{T})$ & $\mathrm{L} \times \mathrm{W}$ & $\mathrm{L} \times \mathrm{T}$ & $\mathrm{W} \times \mathrm{T}$ \\
\hline \multirow{2}{*}{$A$} & 14 August & $7.25 * *$ & $71.97 * * *$ & $92.68 * * *$ & $3.19^{*}$ & $5.00 * * *$ & $4.28 *$ \\
\hline & 28 August & $8.82 * *$ & $39.93 * * *$ & $60.10 * * *$ & $9.54 * * *$ & $6.69 * * *$ & $4.11 *$ \\
\hline \multirow[b]{2}{*}{$g_{\mathrm{sw}}$} & 14 August & $1.75(\mathrm{~ns})$ & $33.78 * * *$ & $14.18 * * *$ & $1.80(\mathrm{~ns})$ & $0.52(\mathrm{~ns})$ & $4.84^{*}$ \\
\hline & 28 August & $2.29(\mathrm{~ns})$ & $33.86 * * *$ & $19.13 * * *$ & $1.17(\mathrm{~ns})$ & $0.29(\mathrm{~ns})$ & 1.78 (ns) \\
\hline \multirow{2}{*}{ IWUE } & 14 August & $10.08 * * *$ & $1.76(\mathrm{~ns})$ & $53.33 * * *$ & $0.95(\mathrm{~ns})$ & $4.56^{* *}$ & $4.01 *$ \\
\hline & 28 August & $5.03 * *$ & $0.01(\mathrm{~ns})$ & $33.01 * * *$ & $5.73 * *$ & $3.37 * *$ & $0.10(\mathrm{~ns})$ \\
\hline
\end{tabular}

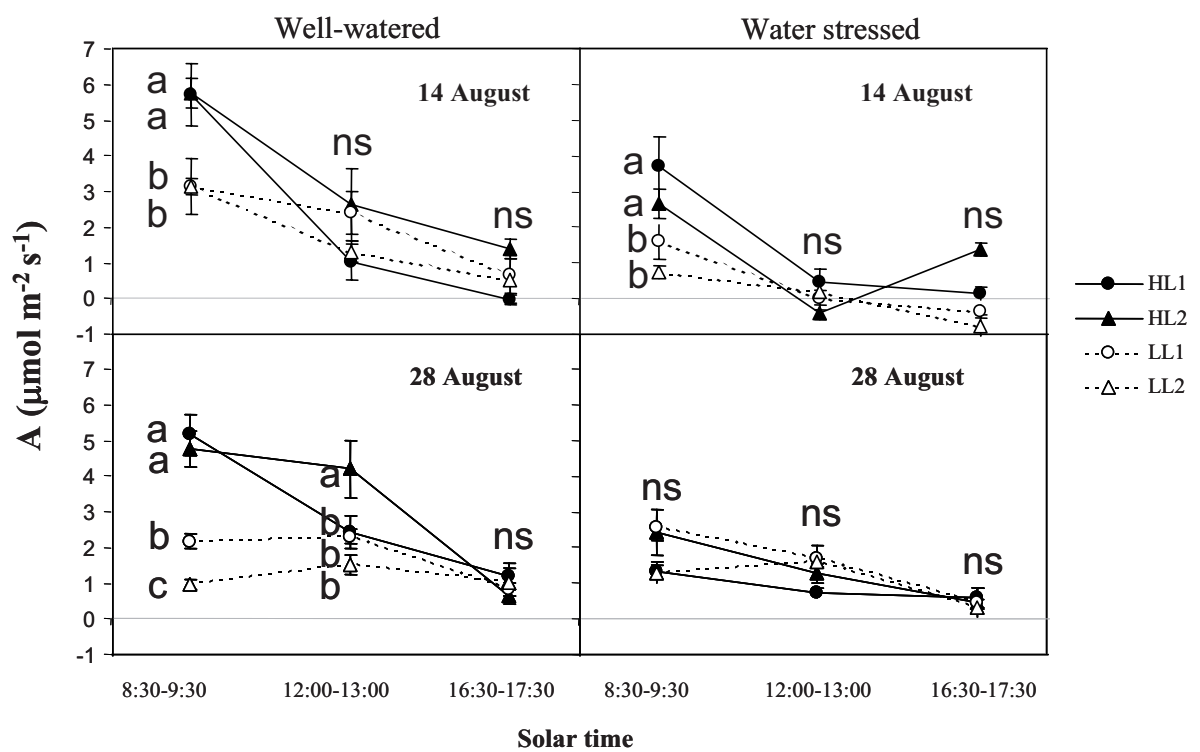

Figure 3. Daily evolution (mean and standard error) of photosynthesis rate $(A)$ under each light treatment conditions (HL1: 66-70\% of full sunlight; HL2: 44-50\%; LL1: 14-16\%; LL2: 5-6\%) in well watered (left) and stressed (right) plants during the two measurement dates (14 August, up; 28 August, down) $(n=5$ for each light $\times$ water treatment $\times$ time of the day). For each time of the day and date, when differences between means are statistically significant, different letters denote differences between light treatments within each water treatment (LSD, $p<0.05)$. Ns: no statistical significance between means.

(Fig. 2). In general, SLA decreased with increasing light availability, but no differences were found between the two high light treatments. Water stress did not affect significantly to foliar anatomy.

\subsection{Water potential}

Water stressed plants showed significantly $(F=61.05$, $p<0.001)$ lower $\psi_{\mathrm{pd}}$ than well-watered seedlings $\left(\psi_{\mathrm{pd}}=\right.$ $-0.74 \pm 0.05 \mathrm{MPa}$ for S plants; $\psi_{\mathrm{pd}}=-0.31 \pm 0.02 \mathrm{MPa}$ for $\mathrm{W}$ plants). Neither statistical differences between light treatments nor interactions between light and water stress treatments were found $(\mathrm{F}=0.42, p=0.74 ; \mathrm{F}=0.39, p=0.76$, respectively). Thus, whatever irradiance, the differences in $\psi_{\mathrm{pd}}$ were related to the watering level. This means that the experimental protocol used to irrigate the seedlings allowed to maintain the same water stress, independently of the light environment.

\subsection{Gas exchange and IWUE under light treatment conditions}

Vapor pressure deficit (VPD) was not statistically different between light treatments for the three times of measurement made during 14 August $(\mathrm{F}=0.6, p=0.62)$, but it was slightly lower in the LL2 treatment for the second measurement date $(\mathrm{F}=4.8, p=0.007)$. VPD was higher in 14 August than in 28 August. For both dates, it was minimum in the morning (ca. $3.5 \mathrm{kPa}$ in 14 August, $2.8 \mathrm{kPa}$ in 28 August) and maximum at midday $(5.3 \mathrm{kPa} ; 3.8 \mathrm{kPa}$ respectively). In general, photosynthetic photon flux density (PPFD) increased with increasing light conditions. PPFD was minimum in the afternoon and maximum at midday (Tab. II). Neither VPD nor PPFD was affected by water treatments, as expected.

Gas exchange parameters followed a similar trend in the two measurement dates. Light, water regime, time of the day and interactions between these three factors were statistically significant for net photosynthesis $(A)$ (Tab. III). Net 


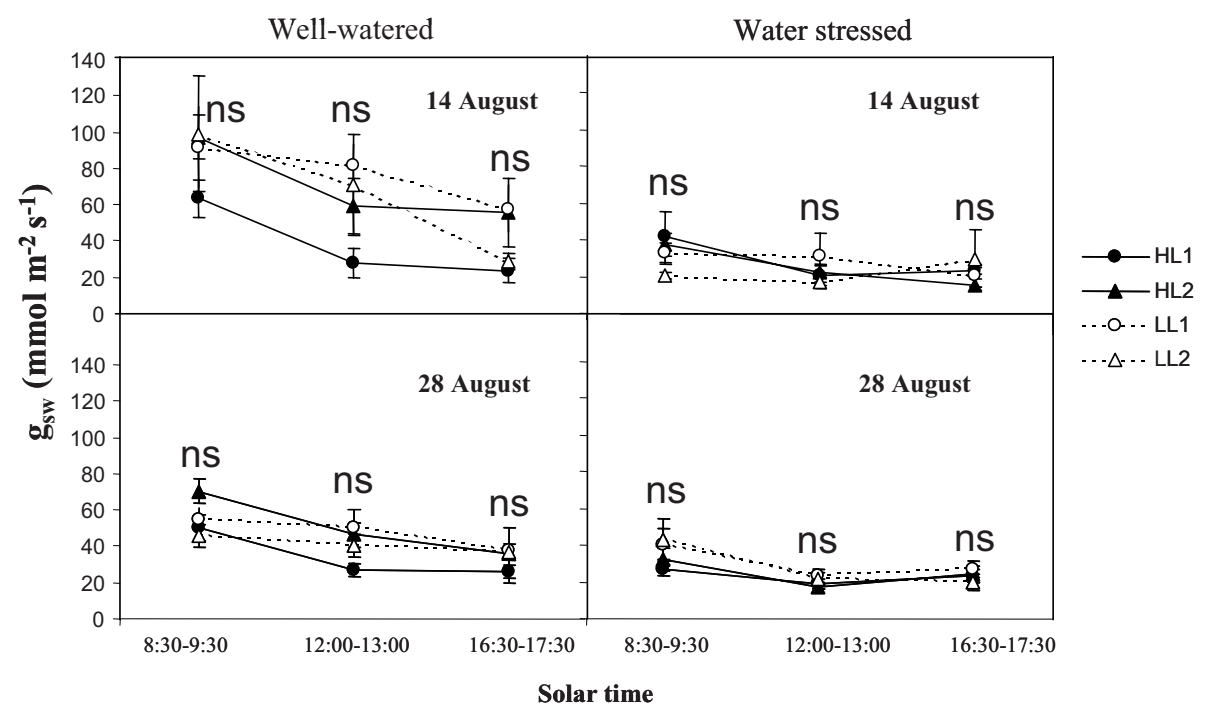

Figure 4. Daily evolution (mean and standard error) of stomatal conductance to water vapor $\left(g_{\mathrm{sw}}\right)$ under each light treatment environment (HL1: 66-70\% of full sunlight; HL2: 44-50\%; LL1: 14-16\%; LL2: 5-6\%) in well watered (left) and stressed (right) plants during the two measurement dates (14 August, up; 28 August, down) $(n=5$ for each light $\times$ water treatment $\times$ time of the day). For each time of the day and date, when differences between means are statistically significant, different letters denote differences between light treatments within each water treatment (LSD, $p<0.05)$. Ns: No statistical significance between means.

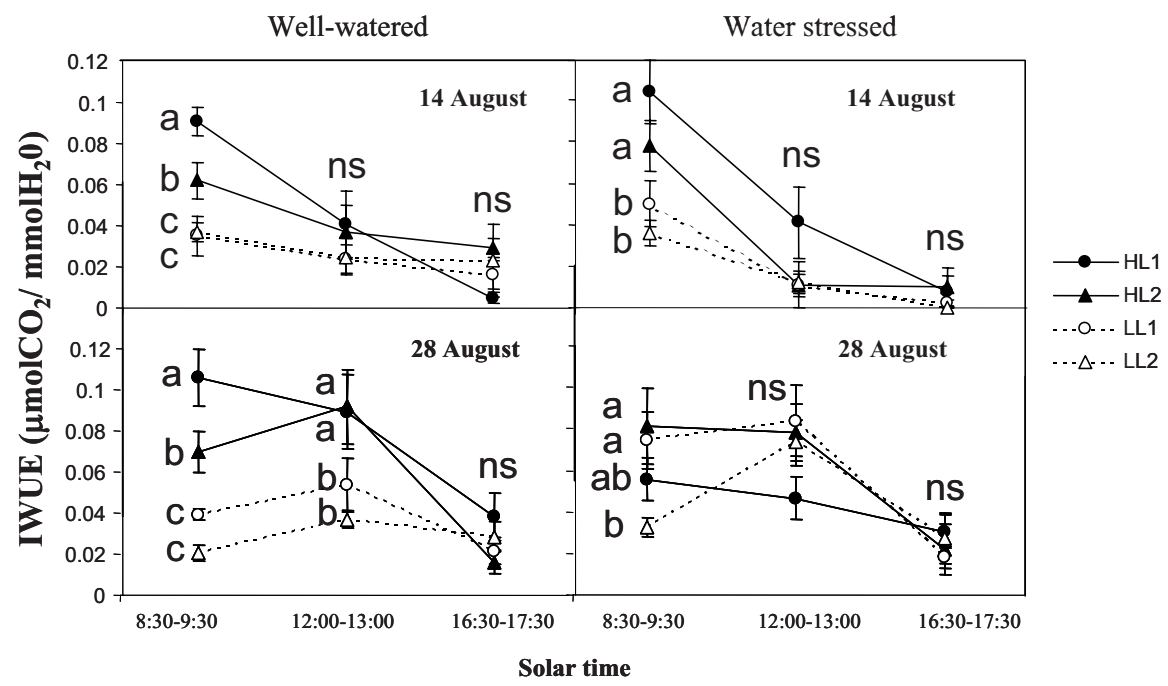

Figure 5. Daily evolution (mean and standard error) of instantaneous intrinsic water use effciency (IWUE) under each light treatment environment (HL1: 66-70\% of full sunlight; HL2: 44-50\%; LL1: 14-16\%; LL2: 5-6\%) in well watered (left) and stressed (right) plants during the two measurement dates (14 August, up; 28 August, down) $(n=5$ for each light $\times$ water treatment $\times$ time of the day $\times$ measurement date). For each time of the day and date, when differences between means are statistically significant, different letters denote differences between light treatments within each water treatment (LSD, $p<0.05$ ). Ns: No statistical significance between means.

photosynthesis rate decreased from its maximum in the morning to its minimum in the afternoon (Fig. 3), but this decline was more pronounced in the first measurement date. For both dates, $A$ was higher in the two high light treatments ( $\mathrm{HL}=\mathrm{HL} 1$ + HL2) at midmorning, except for water stressed seedlings on 28 August, when no differences between light treatments were detected. However, differences between high light and low light environments decreased or even disappeared at noon and in the afternoon. In W plants, HL2 maintained higher $A$ than HL1 at midday in the second measurement date. Water stress reduced $A$ in all the light treatments, but its impact was greater in high light, which reduced the differences between treatments.

Watering treatment, time of the day and their interaction influenced $g_{\mathrm{sw}}$, while light treatment was not significant (Tab. III). Well-watered plants showed higher $g_{\mathrm{sw}}$ than waterstressed plants, though they experienced a strong decline 


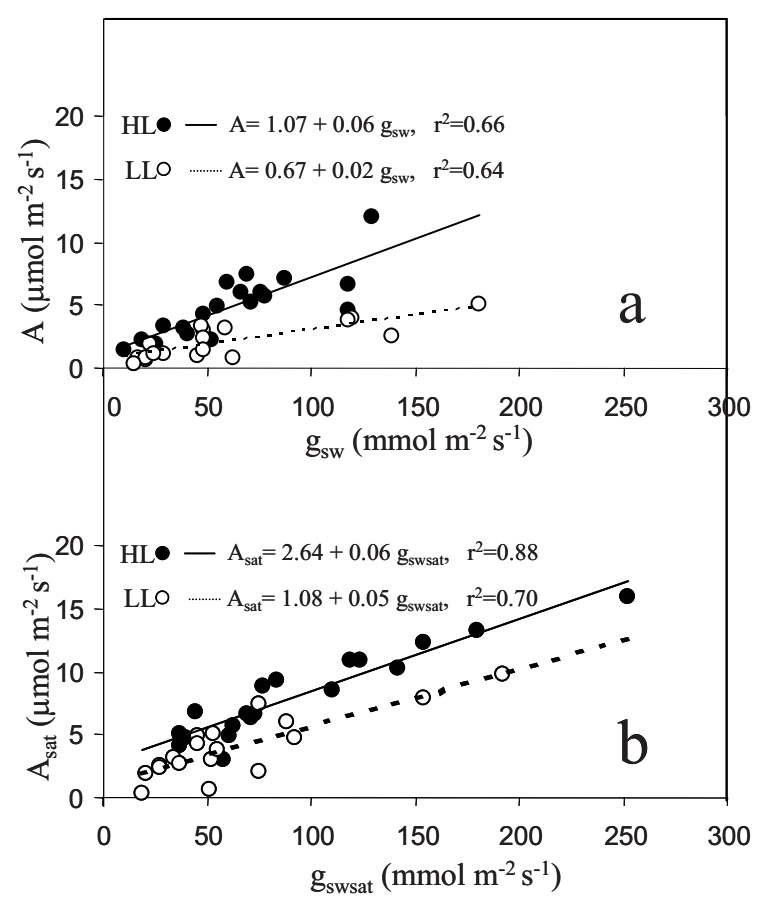

Figure 6. Relationship between photosynthesis rate $(A)$ and stomatal conductance to water vapor $\left(\mathrm{g}_{\mathrm{sw}}\right)$ measured on 14 August under light treatment conditions in the morning (a) and under saturating light (b). HL1 and HL2 values are pooled into high light group (HL) and LL1 and LL2 into low light (LL). All the regressions are significant $(p<0.05)$.

during the day (Fig. 4). Stomatal conductance in S-plants remained more stable.

For both measurement dates and water treatments, IWUE was statistically affected by light treatment, while watering effect was not significant (Tab. III). High light treatments had higher IWUE, but differences disappeared at midday in the first date and in water stressed seedlings in the second date (Fig. 5).

The relationship between $A$ and $g_{\mathrm{sw}}$ in the morning of 14 August also differed between light treatments (Fig. 6a) confirming the differences found in IWUE. Both slope and intercept were significantly different $(\mathrm{F}=44.35 ; p<0.001$ and $\mathrm{F}$ $=12.04 ; p=0.002$, respectively). For a given value of $g_{\mathrm{sw}}, A$ was higher in well illuminated plants. At low $g_{\mathrm{sw}}$, the difference between HL and LL plants decreased.

\subsection{Gas exchange and IWUE under saturating light}

Gas exchange parameters under saturating light followed a similar pattern for the two measurement dates. For W seedlings, $A_{\text {sat }}$ followed a "bell-shaped" pattern, with HL2 exhibiting the highest value (Fig. 7). The difference in $A_{\text {sat }}$ between $\mathrm{W}$ and $\mathrm{S}$ was always maximum for this treatment. Stomatal conductance under saturating light $\left(g_{\text {swsat }}\right)$ was only statistically significant for watering effect and it was lower in S-plants (Tab. IV; Fig. 7). Light treatment was the only factor that increased intrinsic water use efficiency measured
Table IV. Results from the analysis of variance for the gas exchange parameters measured under saturating light in the two measurement dates. F-value and significance is provided (ns: $p>0.05 ; * 0.05 \geqslant$ $p>0.01 ; * * 0.01 \geqslant p>0.001 ; * * * p \leqslant 0.001)$.

\begin{tabular}{lcccc}
\hline \multicolumn{2}{l}{ Source of variation } & Light (L) & Watering (W) & $\mathrm{L} \times \mathrm{W}$ \\
\hline \multirow{2}{*}{$A$} & 14 August & $8.92^{* * *}$ & $11.96^{* *}$ & $1.84(\mathrm{~ns})$ \\
& 28 August & $7.91 * * *$ & $35.46^{* * *}$ & $1.66(\mathrm{~ns})$ \\
\hline \multirow{2}{*}{$g_{\mathrm{sw}}$} & 14 August & $1.78(\mathrm{~ns})$ & $11.08^{* *}$ & $0.93(\mathrm{~ns})$ \\
& 28 August & $2.66(\mathrm{~ns})$ & $26.18^{* * *}$ & $0.61(\mathrm{~ns})$ \\
\hline \multirow{2}{*}{ IWUE } & 14 August & $3.75^{*}$ & $0.37(\mathrm{~ns})$ & $0.55(\mathrm{~ns})$ \\
& 28 August & $3.47^{*}$ & $0.40(\mathrm{~ns})$ & $1.57(\mathrm{~ns})$ \\
\hline
\end{tabular}

under saturating light $\left(I W U E_{\mathrm{sat}}\right)$ in both measurement dates (Tab. IV). In both dates, the most shaded treatment (and LL1 in the second date) showed lower $I W U E_{\mathrm{sat}}$ than HL treatments (Fig. 7).

The relationship between $A_{\text {sat }}$ and $g_{\text {swsat }}$ was similar to the $A-g_{\mathrm{sw}}$, though in this case only intercepts were statistically different $(\mathrm{F}=29.27 ; p<0.001)$ (Fig. 4b).

\section{DISCUSSION}

Light and water availability had a strong influence in morphology and gas exchange traits measured under both saturating and ambient light. In absence of water stress, an intermediate growing light level (44-50\% of full sunlight) maximized the photosynthetic potential capacity (i.e. $A_{\text {sat }}$ ). Thus, under growing light conditions, net photosynthesis rate was similar or even higher in this treatment than in the most illuminated one. This is in agreement with results from other studies on Quercus species which reported higher photosynthesis rate at intermediate light intensities (Castro-Díez et al., 2006; Prider and Facelli, 2004; Valladares et al., 2000).

The two high light treatments had higher photosynthesis rates measured under ambient light than low light treatments. This was associated to thicker leaves under high light environments, which is in agreement with other reported studies (Jurik, 1986; Oguchi et al., 2003). Leaves grown under high light have more chloroplasts in the mesophyll surface, so they must increase the thickness of their palisade parenchyma layer (Terashima et al., 2001). However, biomass accumulation was only impaired in the most shaded treatment, revealing that the differences found in net photosynthesis rate in the instantaneous measurements between the treatments above $5 \%$ of full sunlight did not affect to the overall carbon assimilation during the experiment. Seedlings growing under $15 \%$ of light had thinner leaves and their specific leaf area was higher than in the HL treatments. This conferred them the highest leaf area per plant which counterbalanced their lower photosynthesis rate. Therefore, they accumulated similar amount of biomass than those growing under the high light treatments. This indicates that Quercus suber can grow adequately under such low level of light (15\% of full sunlight) by increasing its specific leaf area (Evans and Poorter, 2001). On the contrary, plants growing under lower light levels $(5 \%)$ could not compensate 


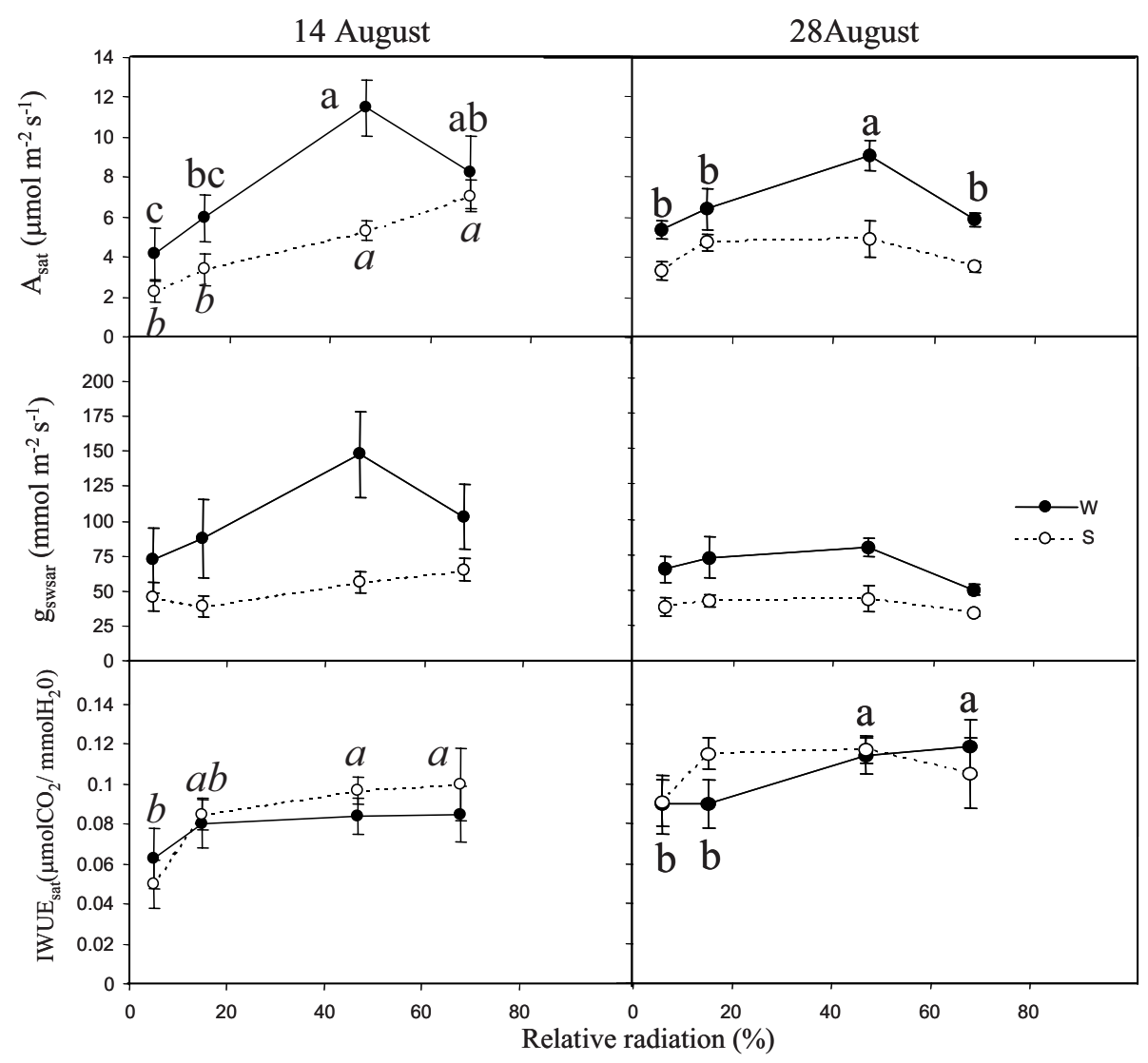

Figure 7. Relationship between gas exchange parameters measured under saturating light (mean and standard error) and the relative radiation of the light treatments respect to the maximum (measured outside the plastic shelter) (HL1: 66-70\% of full sunlight; HL2: 44-50\%; LL1: 14-16\%; LL2: 5-6\%). Water treatments are also considered (W: well watered; $\mathrm{S}$ : water stressed). $A_{\text {sat }}$ : photosynthesis rate. $\mathrm{g}_{\text {swsat }}$ : stomatal conductance to water vapour; $I W U E_{\mathrm{sat}}$ : intrinsic water use efficiency $(n=5)$. When light is statistically significant, different letters denote statistical differences between light treatments within the same water treatment (LSD, $p<0.05)$.

their low photosynthesis rates with a further increase in specific leaf area and, thus, accumulated less biomass than the other treatments. This high efficiency under moderate shade has been observed in other Quercus species. It has been reported even higher biomass accumulation under intermediate light conditions in Quercus pagoda seedlings (Gardiner and Hodges, 1998). It is clear that there is a light threshold where seedling morphological changes can counterbalance the photosynthetic constraints imposed by shade (in cork oak between 5 and $15 \%$ of full sunlight). The determination of this light threshold for Mediterranean species is very important in terms of its ecology and management. Shade enhance microclimatic conditions (decrease temperature and increase air and soil humidity) but decreases growth, therefore the light threshold for seedling optimum performance will determine the specific regeneration niche and the forest management. Obviously, further research in determine this threshold under natural conditions must be needed, since the effect of sun flecks, or other heterogeneity sources are unpredictable.

Water stress and midday depression decreased net photosynthesis in all light treatments, but this decline, in absolute units, was higher in high light treatments. Thus, differences in net photosynthesis across light treatments were not so marked in water stressed seedlings or during midday depression in the measurement dates, especially in the second. This suggests that the environmental conditions during the beginning of dry period in the Mediterranean region, with decreasing soil water availability and increasing water pressure deficits, diminish the absolute impact of light on instantaneous carbon assimilation rates. However, in spite of the clear differences between light and water treatments in biomass accumulation observed at the end of the experiment, no interaction between both treatments was found. Water stress affected equally in all light environments. This could seem to be in contradiction with the results obtained from gas exchange measurements discussed above, which predict that differences in biomass accumulation between the plants growing in the most shaded treatment and the other would be lower in water stressed plants. This difference between instantaneous photosynthesis rates and total carbon gain indicates that the detrimental effect of water stress during the period of application was negligible compared to the effect of deep shade during the whole experiment. This could be the reason of the orthogonal effects of shade and drought on seedling growth found in this work, which is in agreement 
with many other studies (Castro-Díez, 2006; Sack, 2004; Sack and Grubb, 2002).

The relationship between $A$ and $\mathrm{g}_{\mathrm{s}}$ and the calculation of IWUE revealed that water use efficiency was greater in highly illuminated seedlings. These results from instantaneous measurements agree with carbon isotope discrimination measures made in this experiment and published previously (Aranda et al., 2007). Stomatal conductance variation across light environments was smaller than differences in photosynthesis leading to similar water expenses but lower carbon gain in shaded seedlings. This is in agreement with the authors that describe that changes in water use efficiency are driven mainly by changes in photosynthesis rate (Boodrib and Hill, 1998; Piper et al., 2007). However, drought and midday conditions tended to decrease IWUE in the differences between light treatments, since no clear differences between light treatments in IWUE can be found at midday in the first measurement and in water stressed seedlings in the second measurement. Thus, although overall water use efficiency was lower in shaded plants regardless of water stress treatment, these results and those reported by Aranda et al. (2007) suggest that under increasing water deficits, differences in net photosynthesis between light environments tend to disappear and, in turn, differences in water use efficiency tend to be lower.

The patterns described above have several implications for Quercus suber regeneration, cultivation and afforestation: in wet soils, a well illuminated environment maximized photosynthesis and stomatal conductance, while under water stress or during midday depression, light had lower impact on instantaneous gas exchange. Water use efficiency is higher in well-illuminated plants, but water stress also tends to eliminate the differences. However, regardless the water regime applied, Quercus suber were able to maintain an optimum growth under moderate shade (15\% of full sunlight) by increasing their foliar area. Thus, this moderate shade level can be considered the optimum for growth in nursery culture, even if drought conditioning is applied, since minimize water needs without impair its development. Also, this light level could be optimal in cork-oak regeneration in natural stands or in plantation, since it reduces the well known damage of the combination of high light and severe water stress observed in many studies (Eastman and Camm, 1995; Epron et al., 1992; Valladares et al., 2005). With the experimental procedure used in this experiment, we were not able to determine if the morphological and anatomical adaptations to shade (i.e. higher SLA, thinner leaves) could impair the resistance to severe water stress. However, there are evidences from other studies that shade adaptations in Quercus species seem at least not to aggravate the effects of drought (Quero et al., 2006; Sánchez-Gómez et al., 2006). These patterns seem to be confirmed in experiments performed under natural conditions, where the effect of shade provided by nurse plants in newly established seedlings is beneficial (Castro et al., 2004; Gómez-Aparicio et al., 2004), even also when the high light environments are not associated to drier soils, as it suggest the results from treeshelter experiments (Bellot et al., 2002).
Acknowledgements: We acknowledge financial support from the Ministerio de Ciencia y Tecnología through CICYT project AGL2001-2720 and a FPI fellowship granted for M.D. Jiménez. J. Puértolas is supported by the Consolider-Ingenio program 2010 (GRACCIE's project).

\section{REFERENCES}

Aranda I., Gil L., and Pardos J.A., 2001. Effects of thinning in a Pinus sylvestris $\mathrm{L}$. stand on foliar water relations of Fagus sylvatica $\mathrm{L}$. seedlings planted within the pinewood. Trees 15: 358-364.

Aranda I., Pardos M., Puértolas J., Jiménez M.D., and Pardos J.A., 2007. Water use efficiency in cork oak (Quercus suber L.) is modified by the interaction of water and light availabilities. Tree Physiol. 27: 671-677.

Bellot J., Ortiz de Urbina J.M., Bonet A., and Sánchez J.R., 2002. The effects of treeshelters on the growth of Quercus coccifera seedlings in a semiarid environment. Forestry 75: 89-106.

Boodrib T. and Hill R.S., 1998. The photosynthetic drought physiology of a diverse group of southern hemisphere conifer species is correlated with minimum seasonal rainfall. Funct. Ecol. 12: 465-471.

Burslem D.F.R.P., Grubb P.J., and Turner I.M., 1996. Responses to simulated drought and elevated nutrient supply among shade-tolerant tree seedlings of lowland tropical forest in Singapore. Biotropica 28: 636-648.

Canham C.D., Berkowitz A.R., Kelly V.R., Lovett G.M., Ollinger S.V., and Schnurr. J., 1996. Biomass allocation and multiple resource limitation in tree seedlings. Can. J. For. Res. 26: 1521-1530.

Castro J., Zamora R., Hódar J.A. Gómez, J.M., and Gómez-Aparicio L., 2004. Benefits of using shrubs as nurse plants for reforestation in Mediterranean mountains: a 4-year study. Restor. Ecol. 12: 352-358.

Castro-Díez P., Navarro J., Pintado A., Sancho L.G., and Maestro M., 2006. Interactive effects of shade and irrigation on the performance of seedlings of three Mediterranean Quercus species. Tree Physiol. 26: $389-400$.

Cavender-Bares J. and Bazzaz F.A., 2000. Changes in drought response strategies with ontogeny in Quercus rubra: implications for scaling from seedling to mature trees. Oecologia 124: 8-18.

De Lillis M. and Fontanella A., 1992. Comparative phenology and growth in different species of the Mediterranean maquis of Central Italy. Vegetatio 99-100: 83-96.

Duan B., Lu Y., Yin C., Junttila O. and Li, C., 2005. Physiological responses to drought and shade in two contrasting Picea asperata populations. Physiol. Plant. 124: 476-484.

Eastman P.A.K. and Camm E.L., 1995. Regulation of photosynthesis in interior spruce during water stress: changes in gas exchange and chlorophyll fluorescence. Tree Physiol. 15: 229-235.

Epron D., Dreyer E., and Bréda N., 1992. Photosynthesis of oak trees [Quercus petraea (Matt.) Liebl.] during drought under field conditions: diurnal course of net $\mathrm{CO}_{2}$ assimilation and photochemical efficiency of photosystem II. Plant Cell Environ. 15: 809-820.

Evans J.R. and Poorter H., 2001. Photosynthetic acclimation of plants to growth irradiance: the relative importance of specific leaf area and nitrogen partitioning in maximizing carbon gain. Plant Cell Environ. 24: 755-767

Gardiner E.S. and Hodges J.D., 1998. Growth and biomass distribution of cherrybark oak (Quercus pagoda Raf.) seedlings as influenced by light availability. For. Ecol. Manage. 108: 127-134.

Gibelin A.-L. and Déqué M., 2003. Anthropogenic climate change over the Mediterranean region simulated by a global variable resolution model. Clim. Dyn. 20: 327-339.

Gómez-Aparicio L., Zamora R., Gómez J.M., Hódar J.A., Castro J., and Baraza E., 2004. Applying plant facilitation to forest restoration in 
Mediterranean ecosystems: a meta-analysis of the use of shrubs as nurse plants. Ecol. Appl. 14: 1128-1138.

Hastwell G.T. and Facelli. J.M., 2003. Differing effects of shade-induced facilitation on growth and survival during the establishment of a chenopod shrub. J. Ecol. 91: 941-950.

Holmgren M., 2000. Combined effects of shade and drought on tulip poplar seedlings: trade-off in tolerance or facilitation? Oikos 90: 6778.

Holmgren M., Scheffer M., and Huston M.A., 1997. The interplay of facilitation and competition in plant communities. Ecology 78: 19661975.

Jurik T.W., 1986. Temporal and spatial patterns of leaf weight in successional northern hardwood tree species. Am. J. Bot. 73: 1083-1092.

Kubiske M.E., Abrams M.D., and Mostoller S.A., 1996. Stomatal and nonstomatal limitations to photosynthesis in relation to the drought and shade tolerance of tree species in open and understory environments. Trees 11: 73-82.

Montero G. and Cañellas I., 2003. Selvicultura de los alcornocales en España. Silva Lusitana 11: 1-19.

Niinemets U., Sonninen E., and Tobias M., 2004. Canopy gradients in leaf intercellular $\mathrm{CO}_{2}$ mole fractions revisited: interactions between leaf irradiance and water stress need consideration. Plant Cell Environ. 27: $569-583$

Nobel P., 1999. Physiochemical and environmental plant physiology. 2nd ed., Academic Press, San Diego, 474 p.

Oguchi R., Hikosaka K., and Hirose T., 2003. Does the photosynthetic light acclimation need change in leaf anatomy? Plant Cell Environ. 26: $505-512$

Pardos M., Jiménez M.D., Aranda I., Puértolas J., and Pardos J.A., 2005. Water relations of cork oak (Quercus suber L.) seedlings in response to shading and moderate stress. Ann. For. Sci 62: 377-384.

Piper F.I., Corcuera L.J., Alberdi M., and Lusk C., 2007. Differential photosynthetic and survival responses to soil drought in two evergreen Nothofagus species. Ann. For. Sci. 64: 447-452.

Prider J.N. and Facelli J.M., 2004. Interactive effects of drought and shade on three arid zone chenopod shrubs with contrasting distributions in relation to tree canopies. Funct. Ecol. 18: 67-76.

Quero J.L., Villar R., Marañón T., and Zamora R., 2006. Interactions of drought and shade effects on seedlings of four Quercus species: physiological and structural leaf responses. New Phytol. 170: 819-834.

Rousset O. and Lepart J., 1999. Shrub facilitation of Quercus humilis regeneration in succession on calcareous grasslands. J. Veg. Sci. 10: 493-502.
Sack L., 2004. Responses of temperate woody seedlings to shade and drought: do trade-off limit potential niche differentiation? Oikos 107: 107-127.

Sack L. and Grubb P.J., 2002. The combined impacts of deep shade and drought on the growth and biomass allocation of shade-tolerant woody seedlings. Oecologia 131: 175-185.

Sack L., Grubb P.J., and Marañón T., 2003. The functional morphology of juvenile plants tolerant of strong summer drought in shaded forest understories in southern Spain. Plant Ecol. 168: 139-163.

Sánchez-Gómez D., Valladares F., and Zavala M.A., 2006. Performance of seedlings of Mediterranean woody species under experimental gradients of irradiance and water availability: trade-offs and evidence for niche differentiation. New Phytol. 170: 795-806.

Smith T. and Huston M., 1989. A theory of the spatial and temporal dynamics of plant communities. Plant Ecol. 83: 49-69.

Terashima I., Miyazawa S.I., and Hanba Y.T., 2001. Why are the sun leaves thicker than shade leaves? Consideration based on analyses of $\mathrm{CO}_{2}$ diffusion in the leaf. J. Plant Res.114: 93-105

Valladares F. and Pearcy R., 2002. Drought can be more critical in the shade than in the sun: a field study of carbon gain and photoinhibition in a Californian shrub during a dry El Niño year. Plant Cell Environ. 25: 749-759.

Valladares F., Dobarro I., Sánchez-Gómez D., and Pearcy R.W., 2005. Photoinhibition and drought in Mediterranean woody saplings: scaling effects and interactions in sun and shade phenotypes. J. Exp. Bot. 56: 483-494.

Valladares F., Martínez-Ferri L., Balaguer L., Pérez-Corona E., and Manrique E., 2000. Low leaf-level response to light and nutrients in Mediterranean evergreen oaks: a conservative resource-use strategy? New Phytol. 148: 79-91.

Vance N.C. and Zaerr J.B., 1991. Influence of drought stress and low irradiance on plant water relations and structural constituents in needles of Pinus ponderosa seedlings. Tree Physiol. 8: 175-184.

Van Hees A.F.M., 1997. Growth and morphology of pedunculate oak (Quercus robur L.) and beech (Fagus sylvatica L.) seedlings in relation to shading and drought, Ann. Sci. For. 54: 9-18.

Welander N.T. and Ottosson B., 2000. The influence of low light, drought and fertilization on transpiration and growth in young seedlings of Quercus robur L. For. Ecol. Manage. 127: 139-151.

Zavala M.A. and Zea E., 2004. Mechanisms maintaining biodiversity in Mediterranean pine-oak forests: insights from a spatial simulation model. Plant Ecol. 171: 197-207. 